\title{
Experimental model for the study of soft tissue fixation methods on skin-pericranium flaps in rats $^{1}$
}

\author{
William César Cavazana', Roberto Kenji Nakamura Cuman" ${ }^{\mathrm{II}}$, Wilton Mitsunari Takeshita ${ }^{\mathrm{III}}$, Luis Augusto Passeri ${ }^{\mathrm{IV}}$ \\ IFellow PhD degree, Postgraduate Program in Surgery Sciences, Department of Surgery, School of Medical Sciences, State University of Campinas \\ (UNICAMP), Sao Paulo, Brazil. Assistant Professor, Department of Medicine, Center of Health Sciences, State University of Maringa (UEM), Brazil. \\ Conception and design of the study, surgical procedures, acquisition and interpretation of data, manuscript writing. \\ IIPhD, Associate Professor, Department of Pharmacology and Therapeutics, Center of Health Sciences, UEM, Maringa-PR, Brazil. Interpretation of \\ data. \\ IIIPhD, Associate Professor, Department of Odontology, Center of Health Sciences, UEM, Maringa-PR, Brazil. Interpretation of data. \\ ${ }^{\mathrm{IV}} \mathrm{PhD}$, Full Professor, Department of Surgery, School of Medical Sciences, UNICAMP, Campinas-SP, Brazil. Interpretation of data, manuscript \\ writing, critical revision.
}

\section{ABSTRACT}

PURPOSE: To develop an experimental model to study and radiologically monitor displacement of skin flaps in the pericranium of rats subjected to traction and surgical fixation using suture anchored in a skull bone tunnel or with N-butyl-2-cyanoacrylate (Histoacryl ${ }^{\mathrm{TM}}$ ) surgical adhesive.

METHODS: Radiological markers were placed in the subcutis of Wistar rats undergoing subperiosteal detachment of the pericranium with pulling and fixation of the flap. We performed radiography on postoperative days $3,7,14,21$, and 45 . A p-value of $<0.05$ was considered significant.

RESULTS: Qualitative analysis of the data indicated that the flaps in the surgical adhesive group remained in place with no change from the immediate postoperative position. However, the flaps in the suture anchored in the skull bone tunnel group and in the control group showed similar healing, with a loss of attachment of $9.7 \%$ and $22 \%$, respectively, compared with the immediate postoperative position. There was no quantitative difference between the groups.

CONCLUSIONS: This experimental model created acceptable experimental conditions for testing different soft tissue fixation methods. The use of tissue fixatives contributed to better placement of pericranium-cutaneous flaps, and surgical adhesive was superior to suture anchor in the skull bone tunnel for fixation of pericranium-cutaneous flaps.

Key words: Rhytidoplasty. Surgical Fixation Devices. Wound Healing. Adhesives. Rats. 


\section{Introduction}

Skin-periosteal flaps resulting from subperiosteal surgical procedures are used for various purposes and maintaining flap adherence is important postoperatively to preserve the achieved results.

Facial plastic surgery uses various fixation methods to maintain the flap in its new position. The most common are: a) sutures, for retraction and anchoring in a bone tunnel in the skull, or in the temporal fascia, the aponeurotic galea, or periosteal bridges; b) absorbable or metallic devices, such as screws; and c) surgical adhesives ${ }^{1-16}$.

The authors aim to develop an experimental rat model to study and radiologically monitor the movement of pericranial cutaneous flaps during healing and compare flaps which underwent surgical traction and fixation with suture anchored in a skull bone tunnel or surgical adhesive (Histoacryl 0.5g, B Braun, Melsungen, Germany).

\section{Methods}

Approved under protocol number $018 / 2010$ by the Ethics in the Use of Animals Experimentation Committee of the State University of Maringa (Brazil).

A sample of 35 male rats (Rattus norvegicus albinus, Wistar), 120 days of age, weighing 280-484g (average, 365.7g) was used. The rats were randomly distributed into three groups of 10 animals as follows: group A: control; group B: suture anchored in a skull bone tunnel; and group $\mathrm{C}$ : surgical adhesive. The last group of five animals constituted the Sham group (surgical control).

Beginning $24 \mathrm{~h}$ prior to the experiments, the animals were acclimatized in a vivarium and maintained in plastic cages containing a maximum of four animals. The rats received water and food ad libidum, and were maintained at room temperature with 12-h light/dark cycles.

After weighing the animals, the experimental procedure was initiated with intramuscular anesthesia, with chlorhydrate 2-(2.6 xilidine)-5.6-dihidro-4H-1.3-thiazine (Rompun 2\%, Bayer, Sao Paulo-SP, Brazil) at a dosage of $1 \mathrm{mg} / \mathrm{kg}$ and ketamine chlorhydrate (Ketalar, Pfizer, Guarulhos-SP, Brazil) at a dosage of $20 \mathrm{mg} / \mathrm{kg}$, in a 1:1 ratio. Based on the dose of each drug, $1 \mathrm{ml} /$ kgbody weight of the mixture was used for anesthesia ${ }^{1}$.

With the animal anesthetized, the head was shaved followed by antisepsis of the shaved skin with an alcohol solution including $0.5 \%$ clorhexidine (Riohex, Rioquimica, Sao Jose do Rio
Preto-SP, Brazil). Using a 30G $\times 7 \mathrm{~mm}$ needle (PrecisionGlide ${ }^{\mathrm{TM}}$, BD, Sao Paulo-SP, Brazil), the skin was pierced in the frontal region, paramedian, $5 \mathrm{~mm}$ posterior to the nasal root, without transfixing the skin on the contralateral side. A 3-0, 5-10 mm steel thread (Aciflex, Ethicon, Sao Paulo-SP, Brazil) was then introduced through the eye of the needle to the subcutaneous tissue of the punctured region. This steel thread was exposed when the puncture needle was retracted posteriorly, permitting sectioning of the thread with a scissor and the final introduction of the same thread in the subcutaneous tissue using Halsted nippers (Figure 1).

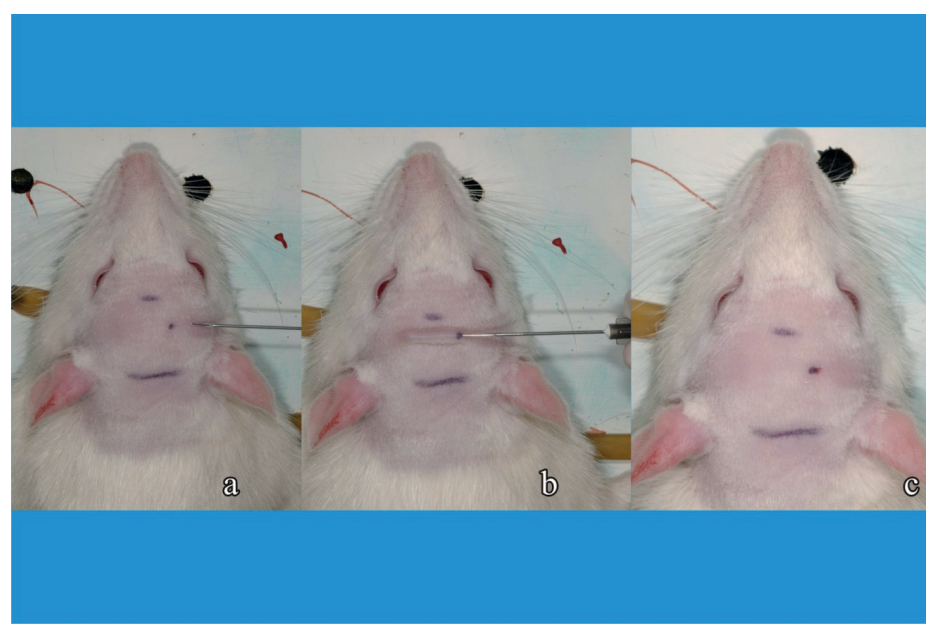

FIGURE 1 - A: 3-0 steel thread segment introduced through the eye of the needle; B: puncture needle retracted posteriorly; C: radiological marker insertion completed.

The function of this implanted thread was to serve as a dynamic radiological marker to observe the mobility of the flap during the study period.

After introducing the radiological marker, the cranium of the animal was immobilized in a cephalostat adapted from a portable computer metal support over a wooden board, to permit pre- and postoperative radiography (Figure 2).

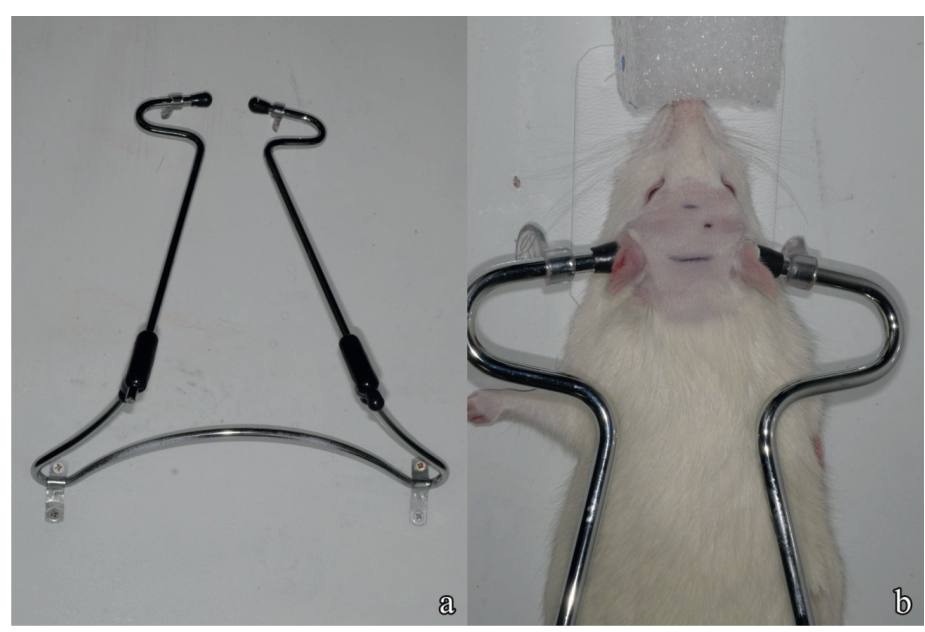

FIGURE 2 - A: cephalostat, B: immobilized cranium. 
Radiographs were taken with the following technique: $27 \mathrm{kVp}$ and $7 \mathrm{~mA}$; 20-cm focal length; and exposure time of 0.06 $\mathrm{s}$, with the central beam perpendicular to the film. We used $57 \times$ $76 \mathrm{~mm}$ occlusal films (Kodak, Sao Jose dos Campos-SP, Brazil). The films were developed in an automatic processor (Revell, XtecRevell, Sao Paulo-SP, Brazil).

The distance corresponding to the measurements obtained in the study was stipulated as the distance between the midpoint of the radiological marker (steel thread) and the most distal point of the left nasal bone of the animal (Measure 1: Preoperative) (Figure 3).

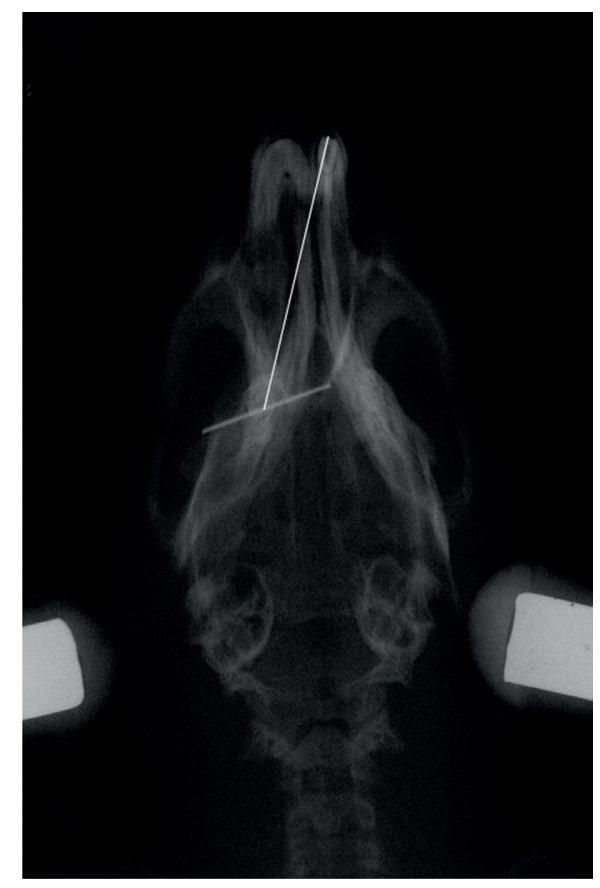

FIGURE 3 - Indicated line shows the reference for the measurements.

Following radiography, the animal was returned to the surgical board to elevate the periosteal-cutaneous flap, apply traction, reposition, and fix using one of the two methods. The skin was again disinfected with a $0.5 \%$ clorhexidine alcohol solution and a 15-mm transverse cutaneous incision was made, corresponding to the posterior border of the auricular pavilion, allowing access to the deep planes and the subsequent incision of the periosteum and thus, the pericranium (Figure 4).

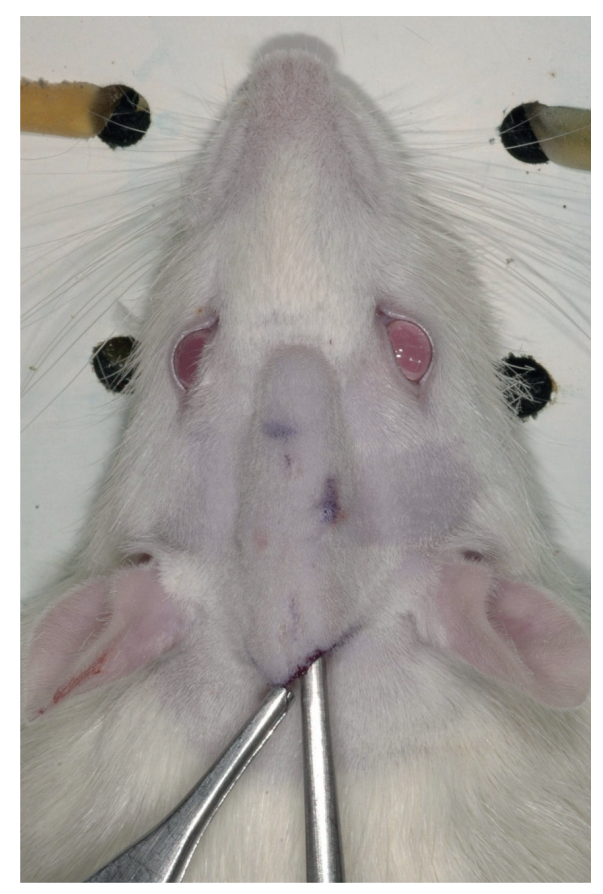

FIGURE 4 - A: incision in the skin and pericranium, B: skull exposure.

The subperiosteal flap was detached from the skull using a Freer elevator, with the nasal dorsum and lateral orbits of the animal as the distal limits. Next, the elevated flap was suspended with the help of an Adson nipper. At this stage, the experimental model is ready to test the various means of fixation (Figure 5).

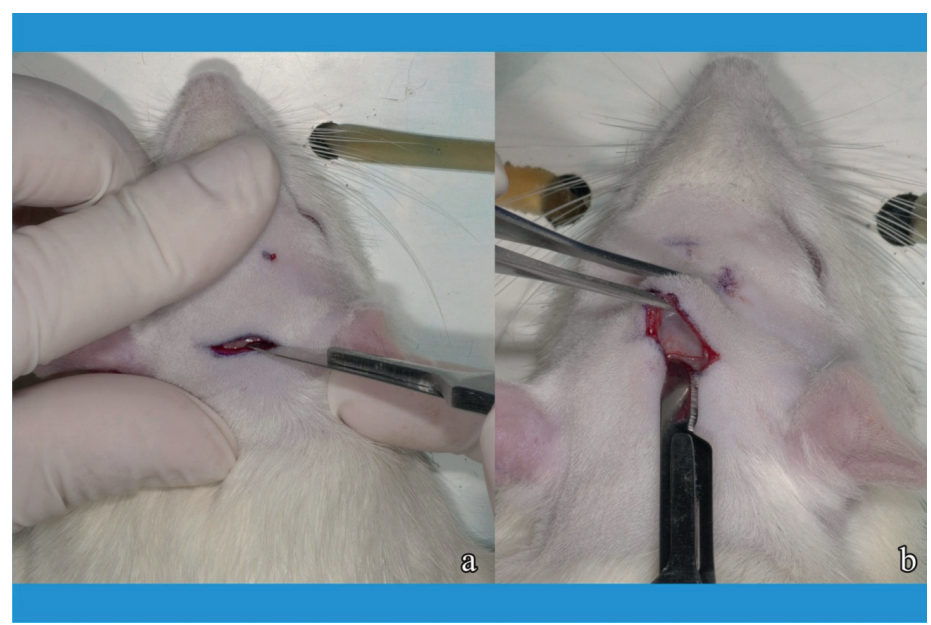

FIGURE 5 - Periosteal-cutaneous flap elevation.

Group A underwent detachment and elevation of the flap, without traction. Group B underwent the creation of two orifices in the skull $4 \mathrm{~mm}$ apart, using a $2-\mathrm{mm}$ round drill bit, preserving the dura-mater, and a 4.0 nylon monofilament (Mononylon, Ethicon) thread was passed through from one opening to the other anchored with a simple suture. The suture was also passed through the periosteum and subcutaneous tissue of the flap to promote and sustain traction on the flap (Figure 6). 


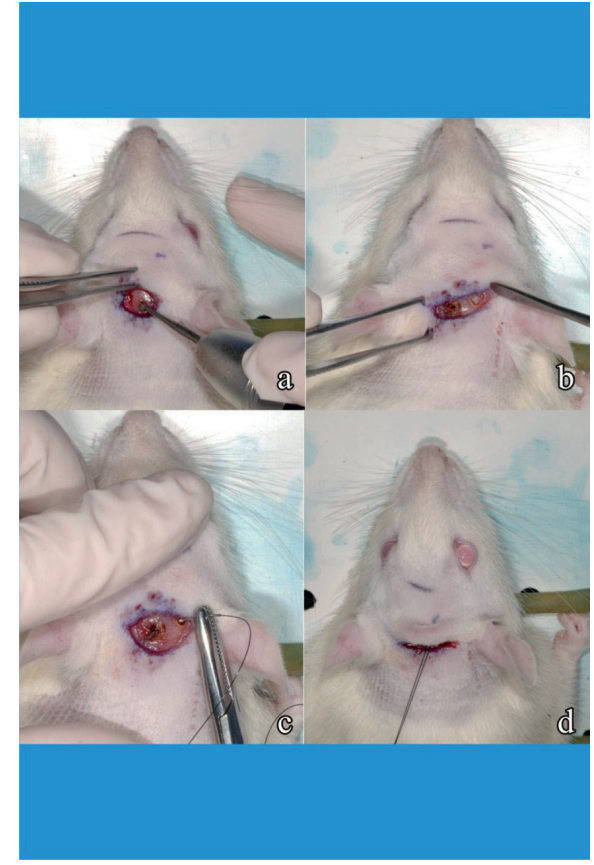

FIGURE 6 - A: round drill bit, B: bone tunnel, C: 4-0 nylon monofilament thread through the bone tunnel, D: retracted flap.

Group C underwent flap traction and received $0.25 \mathrm{ml}$ $(0.25 \mathrm{mg})$ per animal of n-butyl 2-cyanoacrylate surgical adhesive (Histoacryl $0.5 \mathrm{~g}$; B Braun) over the exposed bone of the skull, using the actual ampule with an applicator tip (Figure 7).

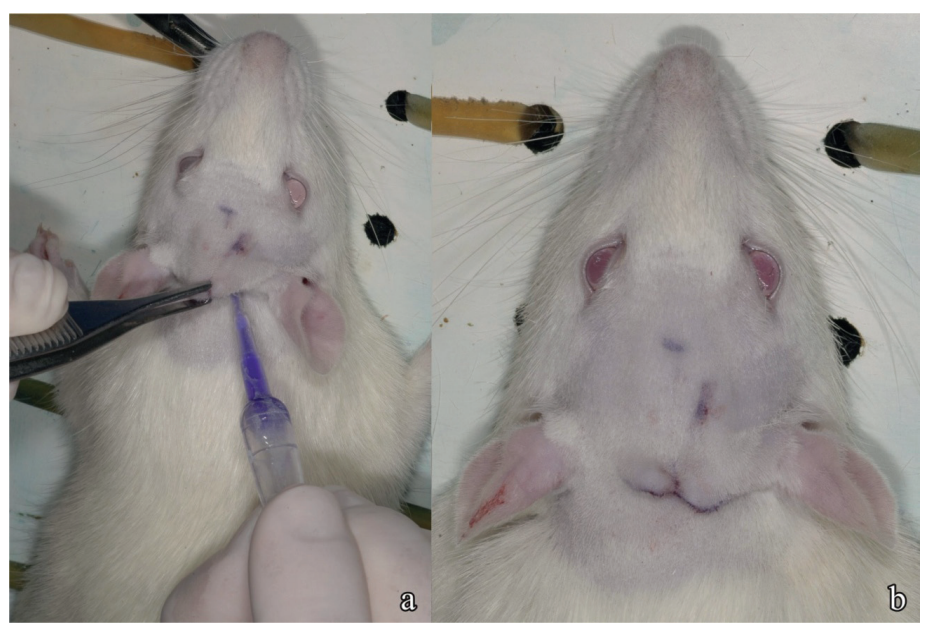

FIGURE 7 - A: n-butyl 2-cyanoacrylate glue application, B: retracted flap.

The Sham group received only the radiological marker in the subcutaneous tissue to indicate the normal mobility of the tissues covering the skull. The skin incisions were sutured with three simple interrupted sutures of 5-0 monofilament nylon (Mononylon, Ethicon).

Radiographs and measurements were repeated postoperatively (Measure 2: Immediate Postoperative). Measure two corresponds to the detachment of the flap, promoted by the traction and maintained by fixation.

The animals received a single oral dose of paracetamol solution (Tylenol, Janssen-Cilag, Sao Paulo-SP, Brazil) at a dosage of $10 \mathrm{mg} / \mathrm{kg}$ by gavage. Recovery occurred in the animals' cages.

The animals operated on underwent radiological evaluations, anesthetized as for surgery, on postoperative day 3,7 , 14,21 , and 45, providing long-term measurements that indicated whether the initial traction of the flap was maintained or not by the fixation.

The radiographs were digitized and the distances between the stipulated points for Measures 1 and 2 were obtained using the software, Image Tool ${ }^{\circledR}$ (Dental Diagnostic Science, UTHSCSA, San Antonio, TX, USA). Measure 2 was then compared with the postoperative measurements (Figure 8).

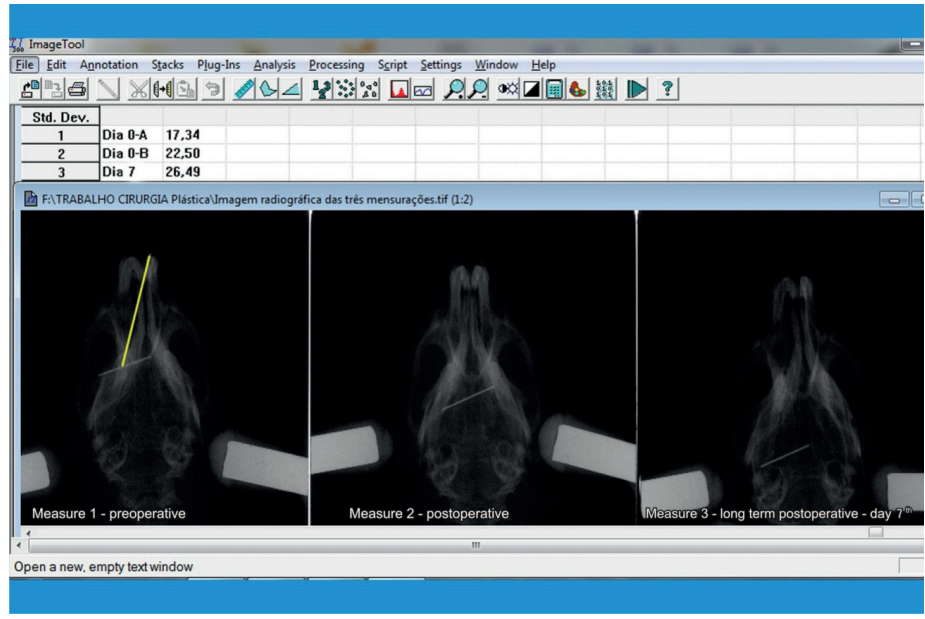

FIGURE 8 - Image analysis using the software, ImageTool ${ }^{\circledR}$ (goup B, rat 4).

Two animals per group were euthanized in ascending numerical sequence using deep anesthesia once the final radiographs were taken and after collecting tissue for histological analysis.

Qualitative data analysis was performed and also ANOVA analysis of variance and Tukey's test with a significance level of $5 \%$.

\section{Results}

No macroscopic tearing of the dura was detected in Group B from the skull perforations and, in most cases, these surgeries were bloodless.

There were no significant differences between the groups over time and between radiological time-points (Table 1). 
TABLE 1 - Mean values of the displacement in millimeters of the radiological markers positioned in the subcutaneous tissue of the cephalic region of Wistar rats, since pre-operative time, for groups A, B, C and Sham, at seven timepoints.

\begin{tabular}{lrrrrrrr} 
& Measure 1 & Measure 2 & Day 3 & Day 7 & Day 14 & Day 21 & Day 45 \\
Group A & 19 & 19.9 & 22.3 & 23.1 & 19.6 & 21.9 & 15.6 \\
Group B & 20.8 & 25.4 & 24.6 & 26.1 & 23.4 & 27.8 & 22.95 \\
Group C & 20.8 & 22.7 & 21.8 & 27 & 25.9 & 21 & 23.05 \\
Sham & 23.5 & 23.5 & 14.7 & 21.8 & 23.9 & 27.1 & 19.1 \\
\hline
\end{tabular}

** ANOVA significance level of 5\%

Qualitative data analysis showed that:

a) Treatment caused $17.1 \%$ greater flap stretching in Group B than in Group A, and 4.3\% greater in Group C than in Group A.

b) On day 3, Groups B and $\mathrm{C}$ had a setback in traction of $3.2 \%$ and $5.7 \%$, respectively, while Group A had a progressive increase in average initial distance of approximately $11.5 \%$ and skin movement in the Sham group tended towards contracture, $37.5 \%$ below the average initial level.

c) On day 7, Groups $\mathrm{B}$ and $\mathrm{C}$ regained the previous decline in distance by $5.7 \%$, and $24 \%$, respectively, while Group A continued to increase the distance, but to a lesser extent, at $3.1 \%$. The movement of the markers in the Sham group tended to return to the initial measurement in amounts similar to those in Group A, while Groups B and C exhibited scar stretching from $2.6 \%$ and $20.9 \%$, respectively.

d) On day 14, skin stretching slowed and decreased 10\% in Group B, 3.7\% in Group C, and 14.8\% in Group A. The Sham group markers essentially returned to their initial positions.

e) On day 21, the scar in Groups A and B stretched $18.8 \%$ and $11.7 \%$, respectively, and at this point Group B reached its maximum stretch of $9.4 \%$ above the immediate postoperative value. Stretching in Group C regressed 19.3\%; 9.1\% below the immediate postoperative value.

f) On day 45, Groups A and B lost the stretch obtained during healing by day 21 and the flaps contracted, causing a decline of $22 \%$ and $9.7 \%$, respectively, far short of the initial average postoperatively. The skin marker in the Sham group also tended to contract, falling $18.7 \%$ compared with the initial mean. Group C restored the stretch at 9.8\%, approximating the immediate postoperative value (Figure 9).

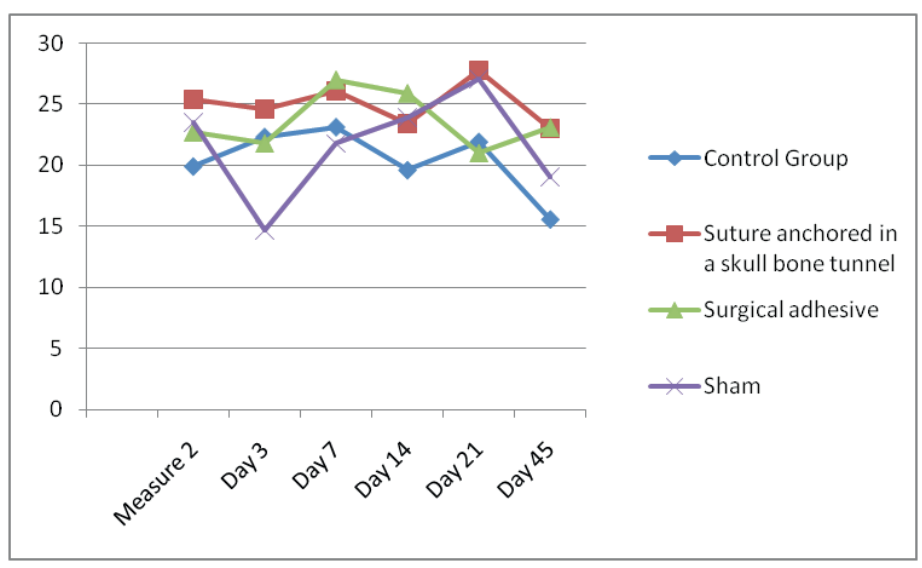

FIGURE 9 - Mean values in millimeters for tissue stretching in groups A, B, C, and Sham, from the time of the operation to the five assessed time points.

\section{Discussion}

The experimental model proposed is easily reproduced and uses easily obtained tools and instruments, therefore filling a void in experimental research in plastic surgery with previous results only in either clinical cases or less commonly, in rabbits ${ }^{17}$. We chose Wistar rats because these animals have a low risk of anesthetic death, are commonly available, are maintained in several research centers, and allow our model to be reproduced with other types of fixation. 
The radiological marker is the essential element in the collection of the dynamic data and its clinical application in rats was also efficient. It was completely inserted in the soft tissues and not free-floating between the periosteum and the skull, which is a concern. It was visible on the radiographs and all of the measurements were taken from its midpoint to the most distal point on the left nasal bone. Its midpoint could also be considered a central axis because of its three-dimensional positioning in the soft tissues. Therefore, minor irregular displacement of its ends or even its length did not influence the measurements.

The need to create a cephalostat led us to create a practical and trustworthy model using a set of mobile supports for a portable computer. This set, attached to a wooden board, allowed for the immobilization of the rat's head and, as a result, the standardization of the radiographs.

Occlusal dental $57 \times 76 \mathrm{~mm}$ radiograph films have dimensions compatible with the anatomical area we studied, facilitating the imaging and allowing for repeatability.

The animals we used were purposefully larger with weights in the range of $350 \mathrm{~g}$. This was important for the surgical procedures and also for imaging records and specimen collection.

An initial number of 15 animals for Group A and for each treated group was not approved by the Ethics in the Use of Animals in Experimentation Committee, reducing the statistical significance.

Following elevation, the periosteal-cutaneous flap delineates a space similar to the optical cavities obtained in endoscopic frontal rhytidoplasty to receive the fixation devices. No skin resection was performed in the flap traction. These three elements (broad subperiosteal detachment similar to an optical cavity, fixation, and no skin resection) reinforce this model for testing fixation in endoscopic frontal rhytidectomy. Gravity could be a confounding variable in human studies; however, gravity appears to have less influence in this model despite the horizontal position of the flap.

The incremental stretching of the pericranium-cutaneous flap in Group A, from days 3-7 suggests that fixation could be disposable. Troilius ${ }^{8}$ advocates that the means of fixation could be expendable in endoscopic frontal rhytidectomy to achieve more natural results. In our study, we found that the control group did not reach the levels of stretching achieved by the treated groups, neither in the immediate postoperative period, nor at the end of the experiment, contrary to the study by Troilius ${ }^{8}$.

Kriet et al. ${ }^{18}$ studied the tensile strength of pericraniumcutaneous flaps using a tensiometer in rabbits that did not receive periosteal fixation, and observed a decrease in tension starting on day 3 postoperatively and a recovery by day 8 postoperatively, which remained until the last measurement on day 28 postoperatively. Romo et al. ${ }^{17}$ observed minimal periosteal adherence in the early postoperative period, which progressed up to 12 weeks in rabbits. The minimum time for periosteal adherence was six weeks. In our study, after a decrease near day 3 , we observed recovery of the amount of stretching of the flaps in the treated groups on day 7. This confirms an effect of tissue fasteners on this recovery, possibly creating a greater inflammatory response and, therefore, greater stretch of the flap in the long term. We saw this in Group B on day 21 and in Group C on days 14 and 45 postoperatively. The greater effect seen in Group $\mathrm{C}$ can also be explained by the exothermic reaction generated in the polymerization of this tissue adhesive $\mathrm{e}^{16,19}$. Contrary to cyanoacrylates, Embucrilate ${ }^{\mathrm{TM}}$ is less toxic with a long chain and a gradual-release reaction ${ }^{20}$. Romo et al. ${ }^{17}$ compared rabbits subjected to subperiosteal coronal rhytidectomy with skin resection and, using an absorbable screw fastener endoscopically and without skin resection, they concluded that the use of continuous semi-permanent fastening means improved accuracy and maintenance of early postoperative results. Although the study was conducted in mice, it showed similar scar behavior to our study, where the final position of the radiological markers after day 21 for the suture anchored in a skull bone tunnel group and after day 45 for the surgical adhesive group surpassed the initial position obtained with surgery, supporting our experimental model.

Graf et al. ${ }^{7}$ analyzed a group of 72 patients who underwent endoscopic frontal rhytidectomy and found that in 38 patients analyzed between 3.5 and 8.5 months, there was a progressive and spontaneous elevation of the medial, central, and lateral areas in both eyebrows and saw the same effect in another 24 patients studied between 3.5 and 24 months. In this study, was found spontaneous stretch in the control group and the Sham group already present in the immediate postoperative period, which progressed by days 3 and 7, when it reached its peak. However, the treated groups also showed peak stretch, at days 7 and 45 in Group C, and at day 14 in Group B, suggesting an effect of the reactivity of the fixation method. Our experimental model appears to reflect situations encountered clinically.

\section{Conclusion}

This experimental model created acceptable experimental conditions for testing different soft tissue fixation methods. The use of tissue fixatives contributed to better placement of pericranium-cutaneous flaps, and surgical adhesive was superior 
to suture anchor in the bone tunnel for fixation of pericraniumcutaneous flaps.

\section{References}

1. Vasconez LO, Core GB, Gamboa-Bobadilla M, Guzman G, Askren C, Yamamoto Y. Endoscopic techniques in coronalbrow lifting. Plast Reconstr Surg. 1994;94:788-93.

2. Ramírez OM. Endoscopic techniques in facial rejuvenation: an overview, part 1". Aesthetic Plast Surg. 1994;18:141-7.

3. Isse NG. Endoscopic facial rejuvenation: endoforehead, the functional lift. Case reports. Aesthetic Plast Surg. 1994;18:21-9.

4. Honig JF, Frank MH, Knutti D, de La Fuente A. Video endoscopicassisted brow lift: comparison of the eyebrow position after endotine tissue fixation versus suture fixation. J Craniofac Surg. 2008;19:1140-7.

5. Citarella ER, Sterodimas A, Condé-Green A. Minimally invasive treatment of dynamic horizontal forehead lines. Plast Reconstr Surg. 2009;124(6):438e-9e.

6. Jones BM, Grover R. Endoscopic brow-lift: a personal review of 538 patients and comparison of fixation techniques. Plast Reconstr Surg. 2004;113:1242-50.

7. Graf RM, Tolazzi ARD, Mansur AEC, Teixeira V, Knize DM. Endoscopic periosteal brow lift: evaluation and follow-up of eyebrow height. Plast Reconstr Surg. 2008;121:609-16.

8. Troilius C. Subperiosteal brow-lift without fixation. Plast Reconstr Surg. 2004;14:1595-603.

9. Badin AZ, Casagrande C, Roberts T 3rd, Saltz R, Moraes LM, Santiago M, Chiaratti MG. Minimally invasive facial rejuvenation endolaser mid-face lift. Aesthetic Plast Surg. 2001;25:447-53.

10. Casagrande C, Saltz R, Chem R, Pinto R, Collares M. Direct needle fixation in endoscopic facial rejuvenation. Aesthetic Surg J. 2000;20:361-7.

11. Holzapfel AM, Mangat DS. Endoscopic forehead-lift using abioabsorbable fixation device. Arch Facial Plast Surg. 2004;6:38993.

12. Berkowitz RL, Apfelberg DB. Preliminary evaluation of a fastabsorbing multipoint fixation device. Aesthetic Surg J. 2008;28:5848.

13. Marchac D, Ascherman J, Arnaud E. Fibrin glue fixation in forehead endoscopy. Plast Reconstr Surg. 1997;100:704-12.

14. Saltz R, Zamora S. Tissue adhesives and applications in plastic and reconstructive surgery. Aesthetic Plast Surg. 1998;22:439-43.

15. Donkerwolcke M, Burny F, Muster D. Tissues and bone adhesiveshistorical aspects. Biomaterials. 1998;19:1461-6.

16. Watté CM, Elks R, Moore DL, McLellan GJ. Clinical experience with butyl-2-cyanoacrylate adhesive in the management of canine and feline corneal disease. Vet Ophthalmol. 2004;7:319-26.

17. Romo T, Sclafani AP, Yung RT, McCormick SA, Cocker R, McCormick SU. Endoscopic forehead-plasty: a histologic comparison of periosteal refixation after endoscopic versus bicoronal. Plast Reconstr Surg. 2000;105:1111-7.

18. Kriet JD, Yang CY, Wang TD, Cook TA. Evaluation of pericranial skull adherence during healing in the rabbit model. Arch Facial Plast Surg. 2003;5:67-9.

19. Mestieri LB, Saska S, Carrodeguas RG, Gaspar AM. Evaluation of n-butyl cyanoacrylate adhesive in rat subcutaneous tissue. Dermatol Surg. 2012;38(5):767-71.

20. Vogel A, O'Grady K, Toriumi DM. Surgical tissue adhesives in facial plastic and reconstructive surgery. Facial Plast Surg. 1993;9:49-57.

\section{Acknowledgements}

To Drs. Lilian Cristina Vessoni Iwaki, Marilliani Chicarelli and Liogi Iwaki Filho of the Department of Odontology of the Maninga State University; Faculty of the Plastic Surgery Division of the Faculty of Medical Sciences at State University of Campinas for their valuable help with this study; Dr. Raimundo Alberto Tostes for his veterinary assistance; PhD student Marcio José Damião, nurse Robério Vive Kananda Emboava, biologist Angela Merceno, and Dr. Dangelo Viel for their support during the surgical procedures, Miss Julia Rowling for partial translation into English, and Edanz for English reviewing.

\section{Correspondence:}

William César Cavazana

Departamento de Medicina

Universidade Estadual de Maringa

Avenida Mandacaru, 1590/Bloco S05/Sala 10

87080-000 Maringá - PR Brasil

Tel.: (55 44)3262-0904

wccavazana@uem.br

Received: June 21, 2013

Review: Aug 20, 2013

Accepted: Sept 19, 2013

Conflict of interest: none

Financial source: Foundation for the Support of Scientific Developement (FADEC).

${ }^{1}$ Research performed at Operative Technique, Experimental Surgery, Metabology and Plastic Surgery, Department of Medicine, Center of Health Sciences, State University of Maringa (UEM), Brazil. Part of $\mathrm{PhD}$ degree thesis, Postgraduate Program in Surgery Sciences, Faculty of Medical Sciences, State University of Campinas (UNICAMP). Tutor: Luis Augusto Passeri. 